\title{
A genetic variant of the atrial natriuretic peptide gene is associated with left ventricular hypertrophy in a non-diabetic population - the Malmö preventive project study
}

Amra Jujić ${ }^{1,2,3^{*}}$, Margret Leosdottir ${ }^{2+}$, Gerd Östling ${ }^{3+}$, Petri Gudmundsson ${ }^{1+}$, Peter M Nilsson ${ }^{3,4+}$, Olle Melander ${ }^{3,4+}$ and Martin Magnusson $2,3+$

\begin{abstract}
Background: Epidemiological studies have shown considerable heritability of blood pressure, thus suggesting a role for genetic factors. Previous studies have shown an association of a single nucleotide polymorphism rs5068 in the NPPA locus gene with higher levels of circulating atrial natriuretic peptide as well as with lower intra individual blood pressure, but up to date, no association between rs5068 and cardiac organ damage, i.e. left ventricular hypertrophy, has been accounted for in humans. We sought to explore if rs5068 is associated with left ventricular hypertrophy as measured by echocardiographic examination in a non-diabetic population.

Methods: 968 non-diabetic individuals from the Malmö Preventive Project (mean age 67 years; 31\% women) were genotyped and examined with echocardiography. Logistic regression was used to adjust for covariates.

Results: The minor allele of rs5068 was associated with decreased prevalence of left ventricular hypertrophy $(p=0.021)$ after adjustment for sex and age. In the multivariate logistic analysis including; age, sex, systolic blood pressure, antihypertensive and/or cardioprotective treatment, body mass index and fasting plasma glucose, the association of rs5068 with left ventricular hypertrophy was, as expected, attenuated ( $p=0.061)$.
\end{abstract}

Conclusion: In a non-diabetic population, the minor allele of rs5068 was associated with lower left ventricular mass.

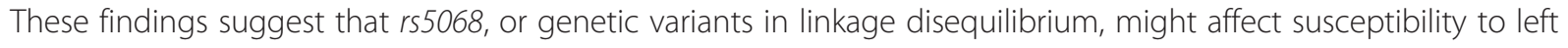
ventricular hypertrophy and support the possible protective role of natriuretic peptides.

\section{Background}

Atrial natriuretic peptide (ANP) and brain natriuretic peptide (BNP) are secreted from cardiomyocytes in response to cardiac wall stress and have important roles in the regulation of extracellular fluid volumes and blood pressure (BP) [1-3]. Animal studies have shown that over expression of natriuretic peptide genes is associated with low BP, whereas under expression is associated with high $\mathrm{BP}$ and left ventricular hypertrophy $(\mathrm{LVH})[4,5]$, and studies on

\footnotetext{
* Correspondence: amra.jujic@mah.se

${ }^{\dagger}$ Equal contributors

'Department of Biomedical Laboratory Science, Malmö University, Malmö,

Sweden

2Department of Cardiology, Skåne University Hospital Malmö, and Lund

University, Malmö, Sweden

Full list of author information is available at the end of the article
}

mice with inactivated type A natriuretic peptide receptors (NPRA) have even shown hypertrophic growth of the heart independently of BP levels [6]. The suppressive effect of ANP on hypertrophy has also been demonstrated in cardiomyocytes in culture [7] and a recent study showed salt-sensitive hypertension in natriuretic peptide precursor A (NPPA) knockout mice, demonstrating that genetically reduced production of ANP can lead to salt-sensitive hypertension [8]. Evidence of substantial heritability of plasma natriuretic peptide (NP) levels has also been accounted for [9] and low circulating NP levels have been associated with obesity [10] and new onset diabetes [11], which may contribute to their predisposition to hypertension.

The NPPA and natriuretic peptide precursor B (NPPB) genes lie in tandem $9.7 \mathrm{~kb}$ apart on chromosome 1 . 
Associations between common variations (rs5068, rs198358 and rs632793) in NPPA-NPPB locus genes and higher levels of circulating ANP were found in a recent study as well as association with lower interindividual BP, with the strongest effect for $r 55068$ [12], findings that have been replicated in larger cohorts [13]. The minor allele of rs5068 has also been associated with favorable cardiometabolic profile [14], and there is evidence for an important protective role of the natriuretic peptides in individuals with coronary artery disease [15], but surprisingly no association with echocardiographic evidence of cardiac organ damage, such as LVH, for this particular SNP. However, since LVH is well known to be overrepresented in patients with diabetes mellitus $[11,16-19]$ the inclusion of subjects with diabetes, $17 \%$ and $15 \%$ respectively) might explain the lack of association of $r 55068$ and LVH [14,15].

Here we tested the hypothesis that $r 55068$ suppressively regulates the development of $\mathrm{LVH}$ in a non-diabetic population.

\section{Methods}

Study sample

Between 1974-1992, birth cohorts (men born in 1921, 1926-1942, 1944, 1946 and 1948-9; women born in 1926, 1928, 1930-6, 1938, 1941-2 and 1949) of inhabitants in Malmö, Sweden, were invited to participate in a large cohort study The Malmö Preventive Project (MPP) with a total of 33,346 individuals attending ( $67 \%$ men, attendance rate $71 \%$, mean age $46 \pm 7$ years). Re-examination of 18,240 surviving MPP participants, the MPP-Re-examination Study (MPP-RES) was conducted during 2002-2006 (63\% men, $72 \%$ attendance rate, mean age $69 \pm 6$ years). All participants answered a self-administered questionnaire on lifestyle and medical history. Height and weight were measured in light in-door clothing, waist circumference was measured and body mass index (BMI) was calculated $\left(\mathrm{kg} / \mathrm{m}^{2}\right)$. Patient BP and pulse rate were measured twice in the supine position after 10 minutes of rest and blood samples were drawn after an overnight fast. In a sample of 1,792 participants, echocardiography (UCG) and electrocardiography (ECG) recordings were carried out. These subjects were randomly selected from groups defined by glucometabolic status: normal fasting plasma glucose (FPG) ( $\leq 6.0 \mathrm{mmol} / \mathrm{l}$ ); impaired FPG (IFG); new-onset type 2 diabetes mellitus; and prevalent diabetes mellitus; with oversampling in groups of subjects with glucometabolic disturbances to ensure sufficient numbers of subjects studied from each group. A full description of this study population has been presented elsewhere [20]. Subjects with prevalent diabetes mellitus type 1 or $2(n=677)$ were excluded from our analysis due to previously shown overrepresentation of diastolic dysfunction and LVH within the diabetic phenotype $[11,16,17]$, resulting in a total of 1,115 subjects. Of these 1,115 subjects, 147 had missing values of one or more covariates used in the multiple regression analysis, resulting in 968 eligible subjects.

All participants signed a written informed consent form before entering the MPP-RES. The study was approved by The Ethics committee at Lund University, Sweden.

\section{Echocardiography}

Conventional echocardiograms were obtained with an Acuson Sequoia, Mountain View, CA, USA (3V2c transducer) or Sonos 5500 Philips, Andover, MA, USA (S3 transducer). All echocardiograms were carried out by experienced sonographers. Internal left ventricular dimensions were evaluated from parasternal long axis view according to the recommendations of the European Association of Echocardiography. Measurements of wall thickness were obtained in two-dimensional end-diastolic parasternal long axis view, where left ventricular mass (LVM) was calculated during a single heart cycle if recordings were homogeneous, otherwise a mean of three to five measurement of different heart cycles was used. LVM was calculated according to clinical standards and indexed for height ${ }^{2.7}$ to minimize the effect of obesity on LVM calculations [21].

Two sonographers analysed images independently from a random sub-sample of subject to test inter- and intra-observer variability which was $13.0 \%$ and $10.5 \%$ for intraventricular end-diastolic septum diameter, and $4.1 \%$ and $3.3 \%$ for left ventricular end-diastolic diameter. Both sonographers were experienced and blinded to clinical data. All analyses were performed offline using Xcelera software (Philips).

\section{Genotyping}

Variants in NPPA-NPPB locus genes were analysed by direct genotyping as described previously using TaqMan (Applied Biosystems) with primers and conditions as recommended by the manufacturer [12]. Twenty five

\section{Table 1 Baseline characteristics of the study population}

\begin{tabular}{llll}
\hline & $\begin{array}{l}\text { Total } \\
\text { sample }\end{array}$ & $\begin{array}{l}\text { Subjects } \\
\text { without LVH }\end{array}$ & $\begin{array}{l}\text { Subjects } \\
\text { with LVH }\end{array}$ \\
\hline $\mathbf{N}$ & 968 & 820 & 148 \\
Sex (\% women) & 30.5 & 30.6 & 29.7 \\
Age (years) & $67.1( \pm 5.7)$ & $66.7( \pm 5.7)$ & $69.4( \pm 5.2)$ \\
Systolic BP (mmHg) & $146.0( \pm 19.3)$ & $145.1( \pm 19.0)$ & $150.8( \pm 20.2)$ \\
Diastolic BP (mmHg) & $84.5( \pm 10.2)$ & $84.2( \pm 10.0)$ & $86.6( \pm 11.3)$ \\
Antihypertensive and/or & 41.3 & 37.8 & 60.8 \\
cardioprotective & & & \\
treatment (\%) & & 71.5 & 91.1 \\
Hypertension (\%) & 74.5 & $26.9( \pm 3.4)$ & $29.8( \pm 4.8)$ \\
BMI & $27.3( \pm 3.8)$ & $5.8[1.0]$ & $6.1[1.0]$ \\
\hline FPG (mmol/l)* & $5.8[0.9]$ & & \\
\hline
\end{tabular}

Data are expressed as mean $( \pm \mathrm{SD})$ or median [interquartile range (IQR)]*. $B P$ blood pressure, $B M I$ body mass index, FPG fasting plasma glucose. 
Table 2 Genotype frequencies of rs5068

\begin{tabular}{|c|c|c|c|c|c|c|}
\hline & \multicolumn{2}{|l|}{ Total sample } & \multicolumn{2}{|c|}{ Subjects without LVH } & \multicolumn{2}{|c|}{ Subjects with LVH } \\
\hline & Frequency (n) & Percent (\%) & Frequency (n) & Percent (\%) & Frequency (n) & Percent (\%) \\
\hline $\mathrm{AA}$ & 847 & 87.5 & 710 & 86.6 & 137 & 92.6 \\
\hline AG & 117 & 12.1 & 106 & 12.9 & 11 & 7.4 \\
\hline GG & 4 & 0.4 & 4 & 0.5 & 0 & 0 \\
\hline Total & 968 & 100 & 820 & 100 & 148 & 100 \\
\hline
\end{tabular}

Genotype frequencies of rs5068 in total sample, subjects without diabetes and subjects with diabetes. Major allele represented by A, minor allele represented by G.

percent of the samples were run in duplicates without discrepancies.

\section{Laboratory assays}

All FPG analyses were performed by Department of Clinical Chemistry, Malmö University Hospital which is attached to a national standardization and quality control system (Beckman Coulter LX20, Beckman Coulter Inc, Brea, USA).

\section{Other definitions}

If LVM was $>51 \mathrm{~g} / \mathrm{m}^{2.7}$, LVH was considered prevalent $[21,22]$. Antihypertensive and/or cardioprotective treatment was defined as use of one or more of the following; $\beta$-receptor blockers, calcium channel blockers, lipid lowering drugs, angiotensin converting enzyme inhibitors, longacting nitrates, angiotensin receptor blockers, digitalis and diuretics. Prevalent hypertension was defined as the presence of either one or more of the following; systolic BP (SBP) $>140 \mathrm{mmHg}$ and/or diastolic BP $>90 \mathrm{mmHg}$ and/or antihypertensive and/or treatment by the time of the third visit. Diabetes was defined as previously known diabetes mellitus type 1 or 2 , whereas new-onset diabetes mellitus type 2 was defined by either two separate measurements of $\mathrm{FPG} \geq 7.0 \mathrm{mmol} / \mathrm{l}$, or one single measurement of $\geq 11.1 \mathrm{mmol} / \mathrm{l}$.

\section{Statistical analysis}

Continuous variables were expressed as mean \pm standard deviation (SD). FPG was not normally distributed and was log transformed prior to analysis. LVM was modeled as the dependent variable in linear regression

Table 3 Left ventricular mass index $\left(\mathrm{g} / \mathrm{m}^{2.7}\right)$

\begin{tabular}{llllll}
\hline LVM index $\left(\mathbf{g} / \mathbf{m}^{\mathbf{2 . 7}}\right)$ & $\mathbf{n}$ & Min & Max & Mean & SE \\
\hline Total population & 968 & 18.96 & 99.31 & 40.44 & 11.28 \\
Subjects without LVH & 820 & 18.96 & 50.97 & 36.86 & 7.13 \\
Subjects with LVH & 148 & 51.00 & 99.31 & 60.21 & 9.36 \\
\hline
\end{tabular}

Values are beta-coefficients (standard errors).

LVM index for the total population, for patients with and patients without LVH. and the presence of LVH via logistic regression with rs5068 genotype as independent variable using additive models with the minor allele (G) coded. All modeling was performed in models adjusted for age and sex (model 1) and for age, sex, BMI, SBP, antihypertensive and/or cardioprotective treatment, and FPG (model 2). A two-tailed significance level of $\mathrm{p}<0.05$ was considered statistically significant. All calculations were done in SPSS 19.0 (SPSS Inc, Illinois, USA).

\section{Results}

Baseline characteristics for the entire non diabetic population and subgroup characteristics (subjects without, and subjects with LVH) are presented in Table 1. The mean age of participants was 67.1 years and $30.5 \%$ of subjects were female. Subjects with LVH were older $(\mathrm{p}<0.001)$, with higher BMI $(\mathrm{p}<0.001)$, SBP $(\mathrm{p}=0.001)$ and higher prevalence of hypertension $(\mathrm{p}<0.001)$ compared to subjects without LVH. Genotype frequencies of rs5068 are presented in Table 2. LVM index for the total population, subjects without LVH and subjects with LVH is presented in Table 3.

In logistic regression analysis, the rs5068 minor allele was significantly associated with lower prevalence of LVH $(\mathrm{p}=0.021)$ (Table 4). However, after adjustment according to model 2 (age, sex, SBP, antihypertensive and/or cardioprotective treatment, BMI and logFPG) this correlation was attenuated $(\mathrm{p}=0.061)$ (Table 5). Results for Hosmer-Lemeshow goodness of fit test as well as sensitivity, specificity and percent of overall correct for model 2 are presented in Table 6.

In linear regression analysis, the minor allele of rs5068 was significantly associated with decreased LVM indexed for height ${ }^{2.7}$ after adjustment according to

Table 4 Association of rs5068 with LVH in a non diabetic population adjusted for age and gender*

\begin{tabular}{llllll}
\hline & B & SE & Wald & P-value & OR $(\mathbf{9 5 \%}$ CI) \\
\hline Gender & -0.331 & 0.203 & 0.656 & 0.103 & $0.72(0.48-1.07)$ \\
Age & 0.095 & 0.017 & 31.205 & $<0.001$ & $1.10(1.06-1.14)$ \\
rs5068 & -0.757 & 0.328 & 5.311 & 0.021 & $0.47(0.25-0.89)$ \\
\hline
\end{tabular}

*Model 1: Age and sex adjusted.

Values are odds ratios ( $95 \%$ confidence intervals) for prevalent LVH. SE values are standard errors. B values are unstandardized regression coefficients. 
Table 5 Association of rs5068 with LVH in a non diabetic population in a fully adjusted model*

\begin{tabular}{lrrrrr}
\hline & B & SE & Wald & p-value & OR (95\% Cl) \\
\hline Gender & -0.460 & 0.225 & 4.165 & 0.041 & $0.63(0.41-0.98)$ \\
Age & 0.101 & 0.019 & 29.714 & $<0.001$ & $1.12(1.07-1.15)$ \\
rs5068 & -0.630 & 0.337 & 3.504 & 0.061 & $0.53(0.28-1.03)$ \\
BP & 0.010 & 0.005 & 4.590 & 0.032 & $1.01(1.00-1.02)$ \\
logFPG & 0.177 & 0.867 & 0.042 & 0.838 & $1.19(0.22-6.53)$ \\
AHT & 0.525 & 0.202 & 6.789 & 0.009 & $1.69(1.14-2.51)$ \\
BMI & 0.191 & 0.027 & 48.988 & $<0.001$ & $1.21(1.15-1.28)$
\end{tabular}

*Model 2: Age, sex, BP, AHT, logFPG and BMI adjusted.

Values are odds ratios ( $95 \%$ confidence intervals) for prevalent LVH. SE values are standard errors. B values are unstandardized regression coefficients.

model $1(p=0.041)$ (Table 7), however after full multivariate adjustment according to model 2 this association was no longer significant $(\mathrm{p}=0.165)$ (Table 8$)$. Seven point six percent of the variation in the response variable can be explained by the explanatory variables. Hardy Weinberg equilibrium significance analysis did not show any significant deviation $(p$-value $=0.117$ ).

\section{Discussion}

The key finding of our study is that the minor allele of rs5068 is associated with lower LVM as well as lower prevalence of LVH in a non-diabetic population after adjustments for age and sex.

These associations were attenuated in the multivariate analysis in which SBP and antihypertensive and/or cardioprotective treatment were included. One possible explanation for this could be that the observed association between the minor allele of $r 55068$ and lower likelihood of LVH is explained by lower BP mediated by the same polymorphism [12]. On the other hand, the attenuation of the association between $r 55068$ and LVH after full adjustment was rather modest, suggesting that the ANP elevating effects of the rs5068 G-allele also may contribute with BP independent effects on LVH. We acknowledge that the effect size is small, as commonly the case is in polygenic situations. However, the effect size

Table 6 Hosmer-Lemeshow goodness of fit test, sensitivity, specificity and percent of overall correct for association of rs5068 and LVH in a fully adjusted model*

\begin{tabular}{ll}
\hline Number of observations & 968 \\
Number of groups & 10 \\
Hosmer-Lemeshow chi2(8) & 10.42 \\
Prob > chi2 & 0.2369 \\
Sensitivity & $15.54 \%$ \\
Specificity & $98.90 \%$ \\
Correctly classified & $86.16 \%$ \\
\hline${ }^{*}$ Model 2: Age, sex, BP, AHT, logFPG and BMI adjusted. &
\end{tabular}

Table 7 Association of rs5068 with LVM Indexed for Height $^{2.7}$ in a non Diabetic Population adjusted for age and sex*

\begin{tabular}{lrrrrrr}
\hline & B & SE & Beta & p-value & $\begin{array}{l}\text { Adjusted } \\
\text { R Square }\end{array}$ & F \\
\hline Age & 0.567 & 0.064 & 0.287 & $<0.001$ & & \\
rs5068 & -2.060 & 1.006 & -0.063 & 0.041 & & \\
Gender & -3.126 & 0.794 & -0.127 & $<0.001$ & & \\
Full equation & & & & $<0.001$ & 0.076 & 27.645 \\
\hline
\end{tabular}

*Model 1. Adjusted for age and sex.

SE values are standard errors. Beta values are standardized regression coefficients. B are unstandarized coefficients.

for most variants is small and a single SNP can only explain a small proportion of the expected heritability.

In contrast to the results of Cannone and co-workers [14], but also Ellis and co-workers [15], we were able to show a significant association between the minor allele of rs5068 and reduced prevalence of $\mathrm{LVH}$, which can be explained by our exclusion of subjects with diabetes. $\mathrm{LVH}$ is heavily overrepresented in patients with diabetes $[19,23]$ and the existence of a specific diabetic cardiomyopathy has been an ongoing debate over the past decades [24]. It is likely to presume that the "harmful" diabetic phenotype overrides the cardioprotective and/or the blood pressure lowering effects of the minor allele of $r s 5068$. Also, in comparison of clinical studies of $\mathrm{LVH}$, adequate correction is of critical importance, since both body habitus and size are associated with LV mass and dimensions. Normalization of LV mass is still a subject for debate, since different criteria for body size adjustment result in different prevalence of patients with LVH. The body surface area correction has been shown to underestimate LVM in the upper range of body surface area distribution, and a height-based adjustment has been proposed to correct for obesity. The most accurate estimation of $\mathrm{LVH}$ appears to be derived from indexing for height ${ }^{2.7}$, where $51 \mathrm{~g} / \mathrm{m}^{2.7}$ appears to be a

Table 8 Association of $r s 5068$ with LVM Indexed for Height $^{2.7}$ in a non diabetic population in a fully adjusted model*

\begin{tabular}{lrrrrrr}
\hline & B & SE & Beta & p-value & $\begin{array}{l}\text { Adjusted } \\
\text { R Square }\end{array}$ & F \\
\hline BP & 0.053 & 0.017 & 0.090 & 0.002 & & \\
FPG & -1.323 & 2.937 & -0.014 & 0.653 & & \\
Age & 0.537 & 0.060 & 0.272 & $<0.001$ & & \\
rs5068 & -1.282 & 0.922 & -0.039 & 0.165 & & \\
BMI & 1.033 & 0.089 & 0.347 & $<0.001$ & & \\
AHT & 2.140 & 0.678 & 0.093 & 0.002 & & \\
Gender & -3.274 & 0.747 & -0.134 & $<0.001$ & & \\
Full equation & & & & $<0.001$ & 0.228 & 41.754 \\
\hline
\end{tabular}

*Model 2: Age, sex, BP, AHT, logFPG and BMI adjusted. SE values are standard errors. Beta values are standardized regression coefficients. 
reliable cut off value to define $\mathrm{LVH}$, as used in our study. [21] As both Cannone and Ellis corrected for body surface area, our results may not be fully comparable.

Echocardiography is the most commonly used imaging modality in assessing LVM, left ventricular size and performance. However, it is subjective and operator dependent and contends with inter- and intraobserver variability, particularly when using harmonic imaging in assessing LVM. Even though harmonic imaging tends to overestimate wall thickness, it has also improved delineation of the left ventricle, especially in subjects with bad image quality [25]. All methods for quantitation of LVM using two-dimensional imaging have been validated previously $[26,27]$. We sought to minimize the effects of subjectivity on our data by testing if inter- and intraobserver variability between two independent readers analysing images was within acceptable levels.

As our sample size was relatively small, the results warrant replication in a larger cohort.

As this is a cross-sectional study, it shares the inherent limitations about causality and control as all crosssectional studies. Still, the genetic effect is not expected to be hampered by such confounding, as the genome is constant throughout life.

Our data was collected at a single regional centre which limits the applicability to other populations and allows the influence of community characteristics. On the other hand, inter-observer bias regarding the UCG measurement was less than would be expected in a multi-centre study. Also, although the subjects with congestive heart failure were overrepresented in the original population, excluding subjects with diabetes resulted in low number of subjects with congestive heart failure $(n=4)$. In order to prove that inclusion of those subjects does not have any impact on our data, we performed a sensitivity analysis by excluding patients with prevalent heart failure and received very similar data (not shown). Hence, inclusion of patients with congestive heart failure is not considered to have any impact on our results.

Finally, our study results may not be generalizable to all ancestries since the study was undertaken in mainly individuals of Swedish descent.

\section{Conclusions}

In a non-diabetic population, the minor allele of $r s 5068$ was associated with lower LVM and lower prevalence of $\mathrm{LVH}$. Whether the association is mediated by the BP lowering effect of $r s 5068$ or is independent of BP is uncertain. However, our findings suggest that $r s 5068$ or genetic variants in linkage disequilibrium might affect susceptibility for LVH and support the possible protective role of NP.

\section{Competing interests}

The authors declare that they have no competing interests.

\section{Authors' contributions}

Drs MM, OM, ML and AJ, have all participated in the conception and design of the study and all authors (Drs MM, OM, ML, PN, GÖ, PG and AJ) have contributed in the analysis and interpretation of data and also in the drafting and revising of the manuscript. Before submission each author have read and thereafter given his final approval of the manuscript. The manuscript has not been published and is not being considered for publication in whole or part in any language.

\section{Acknowledgements}

Funding support was obtained by grants from the Swedish Medical Research Council (OM grant K2009-64X-20129-04-3), the European Research Council (OM grant StG-282255), the Swedish Heart and Lung Foundation (OM), the Medical Faculty of Lund University (OM), Skåne University Hospital (OM, MM), the Albert Påhlsson Research Foundation (OM), the Crafoord Foundation $(\mathrm{OM})$, the Ernhold Lundströms Research Foundation (OM, MM), the Region Skane (OM, MM), the Hulda and Conrad Mossfelt Foundation (OM, MM), the King Gustaf V and Queen Victoria Foundation (OM), the Lennart Hanssons Memorial Fund (OM), Knut and Alice Wallenberg Foundation and the Marianne and Marcus Wallenberg Foundation, the Southwest Skanes Diabetes foundation (OM, MM). The Swedish Heart- and Lung Foundation grant 20060666 (PN, ML). The funding organizations had no role in the design and conduct of the study; the collection, management, analysis, and interpretation of the data; or the preparation or approval of the manuscript.

\section{Author details}

${ }^{1}$ Department of Biomedical Laboratory Science, Malmö University, Malmö, Sweden. ²Department of Cardiology, Skåne University Hospital Malmö, and Lund University, Malmö, Sweden. ${ }^{3}$ Department of Clinical Sciences, Lund University, Skåne University Hospital Malmö, Malmö, Sweden. ${ }^{4}$ Center of Emergency Medicine, Skåne University Hospital Malmö, Malmö, Sweden.

Received: 1 July 2012 Accepted: 20 June 2013

Published: 24 June 2013

\section{References}

1. Inagami T: Atrial natriuretic factor as a volume regulator. J Clin Pharmacol 1994, 34:424-426.

2. Clerico A, Emdin M: Diagnostic accuracy and prognostic relevance of the measurement of cardiac natriuretic peptides: a review. Clin Chem 2004, 50:33-50.

3. Levin ER, Gardner DG, Samson WK: Natriuretic peptides. N Engl J Med 1998, 339:321-328.

4. John SW, Krege JH, Oliver PM, Hagaman JR, Hodgin JB, Pang SC, Flynn TG, Smithies O: Genetic decreases in atrial natriuretic peptide and saltsensitive hypertension. Science 1995, 267:679-681.

5. Melo LG, Steinhelper ME, Pang SC, Tse Y, Ackermann U: Anp in regulation of arterial pressure and fluid-electrolyte balance: lessons from genetic mouse models. Physiol Genomics 2000, 3:45-58.

6. Oliver PM, Fox JE, Kim R, Rockman HA, Kim HS, Reddick RL, Pandey KN, Milgram SL, Smithies O, Maeda N: Hypertension, cardiac hypertrophy, and sudden death in mice lacking natriuretic peptide receptor a. Proc Natl Acad Sci USA 1997, 94:14730-14735.

7. Horio T, Nishikimi T, Yoshihara F, Matsuo H, Takishita S, Kangawa K: Inhibitory regulation of hypertrophy by endogenous atrial natriuretic peptide in cultured cardiac myocytes. Hypertension 2000, 35:19-24.

8. Melo LG, Veress AT, Chong CK, Pang SC, Flynn TG, Sonnenberg H: Saltsensitive hypertension in anp knockout mice: potential role of abnormal plasma renin activity. Am J Physiol 1998, 274:R255-R261.

9. Wang TJ, Larson MG, Levy D, Benjamin EJ, Corey D, Leip EP, Vasan RS: Heritability and genetic linkage of plasma natriuretic peptide levels. Circulation 2003, 108:13-16.

10. Wang TJ, Larson MG, Levy D, Benjamin EJ, Leip EP, Wilson PW, Vasan RS: Impact of obesity on plasma natriuretic peptide levels. Circulation 2004, 109:594-600.

11. Magnusson M, Jujic A, Hedblad B, Engstrom G, Persson M, Struck J, Morgenthaler NG, Nilsson P, Newton-Cheh C, Wang TJ, Melander O: Low plasma level of atrial natriuretic peptide predicts development of 
diabetes: the prospective malmo diet and cancer study. J Clin Endocrinol Metab 2012, 97:638-645.

12. Newton-Cheh C, Larson MG, Vasan RS, Levy D, Bloch KD, Surti A, Guiducci C, Kathiresan S, Benjamin EJ, Struck J, Morgenthaler NG, Bergmann A, Blankenberg S, Kee F, Nilsson P, Yin X, Peltonen L, Vartiainen E, Salomaa V, Hirschhorn JN, Melander O, Wang TJ: Association of common variants in nppa and nppb with circulating natriuretic peptides and blood pressure. Nat Genet 2009, 41:348-353.

13. Newton-Cheh C, Johnson T, Gateva V, Tobin MD, Bochud M, Coin L, Najjar SS, Zhao JH, Heath SC, Eyheramendy S, Papadakis K, Voight BF, Scott LJ, Zhang F, Farrall M, Tanaka T, Wallace C, Chambers JC, Khaw KT, Nilsson P, van der Harst P, Polidoro S, Grobbee DE, Onland-Moret NC, Bots ML, Wain LV, Elliott KS, Teumer A, Luan J, Lucas G, et al: Genome-wide association study identifies eight loci associated with blood pressure. Nat Genet 2009, 41:666-676

14. Cannone V, Boerrigter G, Cataliotti A, Costello-Boerrigter LC, Olson TM, McKie PM, Heublein DM, Lahr BD, Bailey KR, Averna M, Redfield MM, Rodeheffer RJ, Burnett JC Jr: A genetic variant of the atrial natriuretic peptide gene is associated with cardiometabolic protection in the general community. J Am Coll Cardiol 2011, 58:629-636.

15. Ellis KL, Newton-Cheh C, Wang TJ, Frampton CM, Doughty RN, Whalley GA, Ellis CJ, Skelton L, Davis N, Yandle TG, Troughton RW, Richards AM, Cameron VA: Association of genetic variation in the natriuretic peptide system with cardiovascular outcomes. J Mol Cell Cardiol 2011, 50:695-701.

16. Ryden L, Standl E, Bartnik M, Van den Berghe G, Betteridge J, de Boer MJ, Cosentino F, Jonsson B, Laakso M, Malmberg K, Priori S, Ostergren J, Tuomilehto J, Thrainsdottir I, Vanhorebeek I, Stramba-Badiale M, Lindgren P, Qiao Q, Priori SG, Blanc JJ, Budaj A, Camm J, Dean V, Deckers J, Dickstein K, Lekakis J, McGregor K, Metra M, Morais J, Osterspey A, et al: Guidelines on diabetes, pre-diabetes, and cardiovascular diseases: executive summary. The task force on diabetes and cardiovascular diseases of the european society of cardiology (esc) and of the european association for the study of diabetes (easd). Eur Heart J 2007, 28:88-136.

17. Shehadeh A, Regan TJ: Cardiac consequences of diabetes mellitus. Clin Cardiol 1995, 18:301-305.

18. Fang $Z Y$, Prins JB, Marwick TH: Diabetic cardiomyopathy: evidence, mechanisms, and therapeutic implications. Endocr Rev 2004, 25:543-567.

19. Palmieri V, Bella JN, Arnett DK, Liu JE, Oberman A, Schuck MY, Kitzman DW, Hopkins PN, Morgan D, Rao DC, Devereux RB: Effect of type 2 diabetes mellitus on left ventricular geometry and systolic function in hypertensive subjects: hypertension genetic epidemiology network (hypergen) study. Circulation 2001, 103:102-107.

20. Leosdottir M, Willenheimer R, Plehn J, Borgquist R, Gudmundsson P, Harris TB, Launer L, Bjornsdottir H, Nilsson PM, Gudnason V: Myocardial structure and function by echocardiography in relation to glucometabolic status in elderly subjects from 2 population-based cohorts: a cross-sectional study. Am Heart J 2010, 159:414-420. e414.

21. Foppa M, Duncan BB, Rohde LE: Echocardiography-based left ventricular mass estimation. How should we define hypertrophy? Cardiovasc Ultrasound 2005, 3:17.

22. Lang RM, Bierig M, Devereux RB, Flachskampf FA, Foster E, Pellikka PA, Picard MH, Roman MJ, Seward J, Shanewise JS, Solomon SD, Spencer KT, Sutton MS, Stewart WJ: Recommendations for chamber quantification: a report from the American society of echocardiography's guidelines and standards committee and the chamber quantification writing group, developed in conjunction with the European association of echocardiography, a branch of the European society of cardiology. J Am Soc Echocardiogr 2005, 18:1440-1463.

23. Santra S, Basu AK, Roychowdhury P, Banerjee R, Singhania P, Singh S, Datta UK: Comparison of left ventricular mass in normotensive type 2 diabetes mellitus patients with that in the nondiabetic population. $J$ Cardiovasc Dis Res 2011, 2:50-56.

24. Poornima IG, Parikh P, Shannon RP: Diabetic cardiomyopathy: the search for a unifying hypothesis. Circ Res 2006, 98:596-605.

25. Hirata K, Watanabe H, Beppu S, Muro T, Teragaki M, Yoshiyama M, Takeuchi $\mathrm{K}$, Yoshikawa J: Pitfalls of echocardiographic measurement in tissue harmonic imaging: in vitro and in vivo study. J Am Soc Echocardiogr 2002, 15:1038-1044.
26. Helak JW, Reichek N: Quantitation of human left ventricular mass and volume by two-dimensional echocardiography: in vitro anatomic validation. Circulation 1981, 63:1398-1407.

27. Reichek N, Helak J, Plappert T, Sutton MS, Weber KT: Anatomic validation of left ventricular mass estimates from clinical two-dimensional echocardiography: initial results. Circulation 1983, 67:348-352.

doi:10.1186/1471-2350-14-64

Cite this article as: Jujić et al:: A genetic variant of the atrial natriuretic peptide gene is associated with left ventricular hypertrophy in a nondiabetic population - the Malmö preventive project study. BMC Medical Genetics 2013 14:64.

\section{Submit your next manuscript to BioMed Central and take full advantage of:}

- Convenient online submission

- Thorough peer review

- No space constraints or color figure charges

- Immediate publication on acceptance

- Inclusion in PubMed, CAS, Scopus and Google Scholar

- Research which is freely available for redistribution

Submit your manuscript at www.biomedcentral.com/submit
() Biomed Central 